\section{Los autores y las buenas prácticas de publicación: ¿quién decide los criterios?}

\author{
Karen Shashok ${ }^{1}$
}

Un comentario editorial que apareció en el número de junio de 2003 de la Revista Panamericana de Salud Pública/Pan American Journal of Public Health (1) celebró la publicación de "Las buenas prácticas de publicación: recomendaciones para compañías farmacéuticas" (2). En sus consideraciones a propósito de los intereses de los sectores académico, estatal e industrial, el doctor Lolas plantea una cuestión que merece ser examinada en profundidad: las diferencias culturales que existen entre investigadores de distinta procedencia.

\begin{abstract}
No es infrecuente en países con reglamentaciones laxas o imprecisas que se tomen tales estándares por suficientes y que no se sometan a examen por parte de los comités locales de ética. Tal postura es inadecuada, toda vez que un principio esencial de la supervisión en materia de ética es que la lleve a cabo un cuerpo independiente de evaluadores que conozca el entorno concreto en que se realizará el estudio y que tenga en cuenta los factores culturales y sociales pertinentes.
\end{abstract}

Aquí el doctor Lolas se refiere a la tendencia existente en países situados fuera del entorno cultural anglosajón, de aceptar como útiles - sin analizar su idoneidad para el contexto cultural- unas recomendaciones desarrolladas por sus congéneres profesionales de habla inglesa. Cierto es que existen países, organismos y centros que no disponen de una normativa concreta para guiar la conducta profesional de sus investigadores. Sin embargo, no hay motivos para suponer - como parecen hacer algunos editores que no han tenido ocasión de conocer bien otras culturas distintas de la suya propia-que esto se deba a una consciencia ética inferior. Hasta hace poco, los países anglosajones, que parecen ser los emisores de la mayoría de estas recomendaciones, tampoco disponían de normas estrictas. La obligación de tenerlas no surgió por una decisión espontánea de sistematizar y hacer explícita una serie de pautas de conducta, ni por un sentido ético "superior". Surgió, más bien, porque los abusos de las normas que rigen implícitamente en la publicación científica habían empezado a socavar la confianza del público en la buena fe de los investigadores. Los casos que transcendieron a los medios de comunicación social amenazaban con tener consecuencias sociales, políticas y económicas contrarias a los intereses de las agencias públicas que financian las investigaciones, de las empresas que comercializan los productos resultantes y de los centros de investigación que se benefician de la financiación pública y privada. La utilidad de las recomendaciones para las buenas prácticas profesionales es indudable, pero por desgracia su desarrollo no suele ser una medida activa sino reactiva.

De ahí la importancia de que los evaluadores de las buenas prácticas éticas conozcan el entorno concreto en que se realiza la labor científica, para así tener en cuenta los factores culturales y sociales que influyen en las actitudes y creencias de los investigadores. Los factores que determinan el consenso a propósito de las reglas de buena conducta profesional varían según el ambiente local. Y por "local" podemos entender tanto el entorno geográfico (países, regiones, centros y departamentos) como el entorno intelectual (disciplinas, áreas de conocimiento y "escuelas" rivales). No hay motivos para que ningún país se sienta culpable por ocupar una posición que a vista de otros es inferior moralmente, o por tener una normativa "laxa o imprecisa". Las recomendaciones que llegan desde los países anglosajones pueden ser, más 
que un modelo a imitar, un punto de partida para el desarrollo de recomendaciones propias que se ajusten a las necesidades locales. Con el tiempo el Homo sapiens ha dejado de ser identificado como la cumbre de un proceso evolutivo de perfeccionamiento lineal y acumulativo. De igual manera, los "Requisitos uniformes para preparar los manuscritos que se presentan a las revistas biomédicas: redacción y edición de las publicaciones biomédicas" elaboradas por el Comité Internacional de Editores de Revistas Médicas (2) -conocidas como "normas de Vancouver"-, así como las recomendaciones para las buenas prácticas de publicación y otras normas de conducta emitidas desde los puntos de vista de la cultura anglosajona no tienen por qué considerarse la cúspide de la evolución de la ética profesional ni la cumbre que todos deben esforzarse en alcanzar. En algunos entornos, podría merecer la pena escalar otras cumbres de buen comportamiento, igualmente altas, pero de características algo distintas.

Por citar un ejemplo, los investigadores que no pueden adjuntar a sus manuscritos un documento con el visto bueno administrativo de su comité de ética (simplemente porque no existe dicho comité en su lugar de trabajo) no deben sentirse en inferioridad de condiciones a la hora de intentar publicar sus trabajos en una revista que exige este documento. Y los editores deben comprender que la falta de este documento no puede considerarse sin más un indicio de mala práctica ética (como tampoco la existencia de dicho documento puede tomarse como garantía de que la investigación descrita en el manuscrito esté exenta de problemas éticos).

\section{¿QUIÉN DECIDE?}

A pesar de las diferencias ambientales, el objetivo común de cualquier conjunto de recomendaciones destinadas a lograr que se observen las buenas prácticas de publicación debe ser el de velar por los intereses de los usuarios de los resultados de la investigación. Esto nos lleva a una nueva pregunta: si las recomendaciones son buenas y deseables, ¿quiénes serán los encargados de fijar sus términos y de velar por que sean observadas? Sobre este punto no se ponen de acuerdo los expertos que han propuesto normas para el comportamiento de los investigadores. Las diferencias de opinión son especialmente llamativas si estudiamos las distintas propuestas que conciernen al papel específico del editor.

Wager y colaboradores (3) señalan que las responsables de que se observen las recomendaciones del documento "Las buenas prácticas de publicación: recomendaciones para compañías farmacéuticas" son "las compañías farmacéuticas $\mathrm{u}$ otras organizaciones comerciales que patrocinan ensayos clínicos, así como cualquier compañía o persona que colabore en la redacción de publicaciones patrocinadas por la industria farmacéutica". Por lo tanto, sugieren que el impulso para que se desarrollen y observen las recomendaciones éticas debe venir de las empresas farmacéuticas (se podrían sumar a este grupo las compañías fabricantes de instrumental médico y de materiales de laboratorio) y de los proveedores de servicios de redacción y edición.

En la versión más reciente de las normas de Vancouver, los criterios básicos para figurar como autor son, en términos de aportación intelectual, los mismos que antes.

Todos los colaboradores que no satisfagan los criterios de la autoría deben mencionarse en la sección de agradecimientos. Por ejemplo, se puede agradecer la ayuda de una persona que prestó apoyo estrictamente técnico, de alguien que ayudó con la redacción o del director de departamento que sólo brindó apoyo general. También debe reconocerse el apoyo económico y material (2). 
Pero a diferencia de la versión anterior del documento, en la cual se nombraba a los autores y a los editores como los responsables de incluir y publicar información detallada a este respecto, el texto recientemente actualizado - con una redacción menos precisa y de tono más cauteloso- no especifica quién debería ser el responsable de garantizar que los lectores dispongan de esta información. Esta imprecisión parece ser fruto, en parte, del reconocimiento más explícito en las nuevas normas de Vancouver de las posibles diferencias entre revistas (y por lo tanto, entre editores) en cuanto a ciertas políticas específicas.

Los criterios de Wager y colaboradores acerca de las buenas prácticas de publicación (3) coinciden con las normas de Vancouver en recomendar que consten los nombres no solo de los autores, sino de todos los profesionales que hayan ayudado a realizar el estudio, analizar los datos y redactar, revisar o traducir el manuscrito. La diferencia fundamental es que Wager y colaboradores nombran a las empresas farmacéuticas y los proveedores de servicios de redacción y edición como los más indicados para garantizar que los lectores dispongan de esta información, mientras que la versión más reciente de las normas de Vancouver ya no concreta quién debe velar por que esta información aparezca publicada junto al texto en cuestión.

Por su parte, el Council of Science Editors (CSE) parece sugerir que son los editores de las revistas quienes deben asumir la responsabilidad de hacer cumplir las recomendaciones dirigidas a lograr que se observe la buena conducta profesional. Esta sociedad profesional organizó un congreso a comienzos del año 2003 con el fin de conciliar los criterios de autoría para los trabajos publicados y de reconocimiento de las aportaciones que deberían quedar reflejadas en el apartado de los agradecimientos. Según el CSE, la publicación de la lista de "contribuciones" refleja las circunstancias del trabajo intelectual mejor que la lista de "autores" y, de hecho, se pensó que esta propuesta podría acabar por reemplazar los criterios de autoría de las normas de Vancouver (4).

Otro punto de vista a propósito de las diferencias culturales entre editores y autores es el expuesto por Crane en el Draft White Paper (Borrador de Informe) sobre los criterios de autoría de la CSE (5). Crane nos recuerda que algunos investigadores podrían rechazar la idea de que sean los editores quienes impongan los criterios y quienes pretendan ejercer de "agentes de policía" para cerciorarse de que estos criterios sean observados (5). No obstante, este autor insta a editores y autores a rechazar la práctica de firmar como autor sin serlo (guest author o gift author), y de firmar o publicar un trabajo escrito por un redactor profesional cuyo nombre no conste (ghost author). De acuerdo con lo expuesto en "Las buenas prácticas de publicación" Crane también considera necesaria la participación de los centros de investigación y de los organismos que los financian para eliminar estas dos manifestaciones de abuso ético. Esta autora sugiere que los editores deberían ser "innovadores que presentan alternativas y que abogan por su aplicación por parte de los que contribuyen a la literatura científica, las instituciones y los organismos financieros de los que aquellos dependen" (5).

Otras medidas, sugeridas en las páginas de Science Editor (la revista del CSE), vuelven a plantear la colaboración entre editores y autores para garantizar la transparencia cuando se trata de estudios que se han realizado con el apoyo financiero del sector comercial. Korenman (6) propone que sean los editores de las revistas quienes exijan a los autores (sean estos empleados de una empresa privada o del sector académico) que confirmen de manera específica y por escrito varios puntos concretos: 1) que han dado su visto bueno a los protocolos de investigación, 2) que conocen el proceso de análisis de los datos, 3) que avalan los resultados, y 4) que apoyan cada una de las conclusiones (6). Como una forma de implicar también a los autores en el sis- 
tema de responsabilidad profesional, Korenman propone que si estos no pueden confirmar los cuatro puntos por escrito, no deben permitir que su nombre aparezca en el artículo.

En un comentario editorial, la revista Nature subrayó los problemas prácticos y éticos que surgen en torno a los grandes estudios realizados "en equipo". Cuando la investigación es realizada por numerosos colaboradores de distintos centros, "las peleas por ocupar un lugar en la portada del manuscrito pueden echar a perder el espíritu de colaboración" (7). El comentarista de Nature recomienda, como solución, que al comenzar el trabajo en equipo los colaboradores mismos establezcan, mediante un proceso de negociación, una política concreta con respeto a las publicaciones. Se constató que una simple lista de autores no "medía" con exactitud la contribución real de cada uno de los miembros del equipo. En ese comentario editorial se recomendó a los editores de revistas científicas que fuesen más flexibles y permitiesen utilizar en estos casos sistemas alternativos de autoría para reflejar la contribución real de cada autor. Aunque se acogió con entusiasmo la idea de obligar a las revistas a añadir en cada artículo una lista completa de la contribución específica de cada autor, la reacción de los editores, según Nature, fue más bien recelosa (7).

Un caso reciente de retractación de un artículo publicado reveló, una vez más, las diferencias de criterio entre autores y editores. Aunque la necesidad de retractar el artículo en cuestión se hizo evidente tras una investigación realizada por la universidad donde trabajaba el primer autor, la notificación oficial por parte de la revista tardó casi un año más en publicarse, debido a que los autores se resistían a aceptar la medida y las negociaciones con los editores se prolongaron. Al final, transcurrieron tres años y medio entre la publicación del artículo y su retractación formal. Este periodo pudo ser lo suficientemente largo como para aminorar el efecto del "castigo" a los autores malhechores, y la retirada formal de parte de la revista pudo llegar demasiado tarde para corregir el archivo científico. (Muchos investigadores que ya habrán citado el artículo retractado no se darán cuenta de que se ha declarado que no tiene validez.) En palabras de un investigador con experiencia en el análisis de casos de mala conducta científica, las revistas (es decir, los editores) deben defender su reputación y para ello deben "tomar las medidas necesarias por su cuenta cuando una investigación saca a la luz errores y es difícil localizar a los autores, o cuando estos se resisten a retirar el artículo" (8). En otras palabras, el autor consultado afirmaba que los editores deberían ser muy firmes a la hora de corregir los errores que conducen a la publicación de información engañosa. Sin embargo, parece que el editor en este caso anduvo con pies de plomo.

A pesar de la multitud de recomendaciones que existen para definir las buenas prácticas profesionales, no hay consenso entre las diferentes autoridades sobre quiénes deben ser los encargados de garantizar que se cumplan. En el fondo, son los lectores quienes deben marcar los límites entre lo aceptable y lo inaceptable. Al intentar defender sus intereses como científicos, deben recibir el apoyo de los editores de las revistas, de las compañías farmacéuticas y de los profesionales que proporcionan servicios de redacción, revisión editorial o traducción. Sin embargo, es necesario recordar que en algunas situaciones, los intereses de los autores o de los que han aportado los medios para que estos hagan su trabajo pueden no coincidir totalmente con los intereses de los lectores. Este es un factor importante que puede afectar a lo que el doctor Lolas ha llamado la legitimidad de la publicación médica (1). Los lectores necesitan juzgar el valor científico de un artículo, los méritos de una solicitud de apoyo financiero a la investigación, o la validez del expediente para la aprobación de un fármaco nuevo. Para que puedan hacerlo debe regir, a la hora de aclarar el origen de la investi- 
gación y explicar el papel de las distintas partes responsables, la misma "cultura de transparencia" que rige al informar de los métodos de obtención y análisis de los datos.

Agradecimientos. A Enrique García Olivares por su ayuda en la revisión del uso del español en este manuscrito, y a los editores de la Revista Panamericana de Salud Pública por mejorar aún más el texto definitivo.

\section{REFERENCIAS}

1. Lolas F. La ética de la publicación médica: entre la academia, el estado y la industria. Rev Panam Salud Publica 2003:14(1):1-2.

2. Comité Internacional de Editores de Revistas Médicas. Requisitos uniformes para preparar los manuscritos que se presentan a las revistas biomédicas: redacción y edición de las publicaciones biomédicas [traducción al español de International Committee of Medical Journal Editors. Uniform Requirements for Manuscripts Submitted to Biomedical Journals. (sitio en Internet). Hallado en: http://www.icmje.org. Acceso el 9 de enero de 2004]. Rev Panam Salud Publica 2004;15(1):47-51.

3. Wager E, Field EA, Grossman L. Normas para la publicación de investigaciones clínicas patrocinadas por la industria farmacéutica [traducción al español de Wager E, Field EA, Grossman L. Good publication practice for pharmaceutical companies. Curr Med Res Opinion 2003;19(3):149-154]. Rev Panam Salud Publica 2003:14(1):64-66.

4. Friedman PJ. A new standard for authorship. Council of Science Editors. [sitio en Internet]. Hallado en: http://www.councilscienceeditors.org/services_FriedmanArticle.shtml. Acceso el 9 de febrero de 2003.

5. Biagioli M, Crane J, Derish P, Gruber M, Rennie D, Horton R. CSE Task Force on Authorship. Draft White Paper [sitio en Internet]. Encontrado en: http://www.councilscienceeditors. org/services/atf_whitepaper.cfm? Acceso el 15 de septiembre de 2003.

6. Korenman SG. The role of journal editors in the responsible conduct of industry-sponsored biomedical research and publication: a view from the other side of the editor's desk. Science Editor 2003;26(2):42-43.

7. Anonymous. Who'd want to work in a team? [Editorial]. Nature 2003;424(6944):1.

8. Abbott A. Retraction ends furor over cancer vaccine. Nature 2003;425(6953):4. 